\title{
ANALISIS SETTING PENGAMAN TRANSFORMATOR DAYA DI GARDU INDUK NUSA DUA JIKA TERJADI GANGGUAN HUBUNG SINGKAT SATU PHASA TANAH
}

\author{
I Gusti Agung Putra Sanjaya ${ }^{1}$, I Gede Dyana Arjana ${ }^{2}$, I Wayan Rinas ${ }^{3}$ \\ Jurusan Teknik Elektro dan Komputer, Fakultas Teknik, Universitas Udayana \\ Email: agungputra101@yahoo.com ${ }^{1}$, dyanaariana@unud.ac.id ${ }^{2}$, rinas@unud.ac.id ${ }^{3}$
}

\begin{abstract}
ABSTRAK
Relai REF (Restricted Earth Fault) digunakan sebagai peralatan pengaman dari gangguan hubung singkat satu phasa ke tanah, agar arus gangguan tidak mengalir ke titik netral trafo saat putusnya kawat NGR (Neutral Ground Resistor). Arus hubung singkat satu phasa ke tanah sebelum putusnya Pengawatan NGR sebesar 288,67 Ampere, sedangkan arus hubung singkat sesudah putusnya Pengawatan NGR sebesar 884,15 Ampere. Hasil analisis pemasangan relai REF pada trafo 60 MVA terhadap gangguan hubung singkat satu phasa ke tanah saat putusya pengawatan NGR mempunyai kemampuan proteksi yang baik berdasarkan dari perhitungan simulasi gangguan saat putusnya Pengawatan pentanahan NGR, dengan arus hubung singkat sebesar 884,15 Ampere, maka besar arus yang mengalir pada relai REF sebesar 0,263 Ampere, sedangkan relai REF di setting pada 0,233 Ampere, maka dapat di pastikan relai REF sudah bekerja, karena waktu kerja relai REF adalah 0 detik atau tanpa waktu tunda.
\end{abstract}

Kata Kunci : Relai REF, Arus Hubung Singkat, Pengawatan NGR

\begin{abstract}
REF (Restricted Earth Fault) Relay is used as protective equipment against single phase short circuit to the ground. It prevents the interference current from flowing into the transformer neutral point when the Neutral Ground Resistor (NGR) wire terminates. The single phase shortcircuit current to the ground before the wiring termination was 288.67 NGR Ampere, whereas the short circuit current after the termination was 884.15 Ampere NGR. An analysis of the REF relay's installation on transformer at 60 MVA against short circuit current single phase to ground during the termination of NGR wiring was conducted. The results showed a reasonably good protection capability based on the calculation of the current interruption simulation during the NGR ground wiring termination with the short circuit current of 884.15 Ampere. This finding means that the flow of the current on REF relay was at 0.263 Ampere, while the REF relay was set at 0.233 Ampere. Thus, it can be assured that the REF relay works properly, because the $R E F$ relay's working time is 0 second or without time delay.
\end{abstract}

Key words:REF relay, short circuit current, NGR

\section{PENDAHULUAN}

Sistem pentanahan langsung adalah dimana titik netral sistem dihubungkan langsung dengan tanpa memasukan suatu impedansi. Salah satu tujuan sistem pentanahan titik netral adalah untuk membatasi tegangan dari fasa-fasa yang tidak terganggu bila terjadi gangguan fasa ke tanah [1]. Peralatan pengaman untuk trafo daya secara khusus tidak tersedia, maka untuk keamanan harus di batasi arus maksimal 300 A dengan cara memasang NGR (Neutral Ground Resistor) 40 Ohm. Jika NGR tidak berfungsi, maka arus gangguan akan langsung mengalir ke titik netral trafo sehingga tidak dapat melindungi trafo jika terjadi gangguan hubung singkat satu phasa tanah. Relai REF (Restricted Earth Fault) diperlukan jika terjadi kegagalan pada NGR untuk melindungi trafo. Seperti yang terjadi di Gardu Induk Nusa Dua saat 
putusnya kawat pentanahan NGR 40 Ohm pada trafo 3 yang menyebabkan besarnya arus gangguan hubung singkat satu phasa ke tanah. Gardu Induk Nusa Dua terletak dipinggir laut dan dalam posisi outdor, maka akan terjadi korosi yang tinggi sehingga terminal tidak berfungsi dengan baik dan menyebabkan putusnya kawat pentanahan NGR 40 Ohm.

Jenis sistem pentanahan dengan NGR merupakan sistem pentanahan yang paling banyak digunakan pada PT. PLN (persero) selain jenis sistem pentanahan langsung (solid grounding). Sistem pentanahan menggunakan NGR dipakai pada sistem sekunder trafo daya untuk mengurangi arus gangguan, karena dikhawatirkan banyak terdapat gangguan yang bisa membahayakan trafo[1].

Studi dilakukan dengan cara mengumpulkan data-data seperti: data trafo $3 \mathrm{GI}$ Nusa Dua, data relai REF dan analisis ini dilakukan dengan perhitungan manual.

\section{KAJIAN PUSTAKA}

Gangguan hubung singkat adalah gangguan yang terjadi karena adanya kesalahan antara bagian-bagian yang bertegangan diakibatkan dari timbulnya arus yang jauh lebih besar dari pada arus normal. Gangguan hubung singkat yang mungkin terjadi di dalam jaringan sistem kelistrikan adalah gangguan arus hubung singkat satu phasa ke tanah.

Untuk mendapatkan nilai arus hubung singkat satu phasa ke tanah maka diperlukan nilai dari perhitungan menggunakan persamaan umum [2]:

\subsection{Menghitung Daya Hubung Singkat} Trafo

Perhitungan daya hubung singkat trafo menggunakan persamaan (1) sebagai berikut [2] :

$$
M V A_{h s}=\sqrt{3} x k V_{L L} x I_{h s} M V A
$$

Keterangan :

$M V A_{h s}$ adalah daya hubung singkat trafo

$k V_{L L} \quad$ adalah tegangan dasar

$I_{h s} \quad$ adalah arus hubung singkat trafo

\subsection{Menghitung Impedansi Dasar Trafo} Perhitungan Impedansi Dasar Trafo menggunakan Persamaan (2) sebagai berikut [2] :

$$
\mathrm{Z}_{\mathrm{d}}=\frac{\mathrm{kV}_{\text {dasar }}^{2}}{\mathrm{MVA}_{\text {dasar }}}
$$

Keterangan :

$\mathrm{Zd}$ adalah impedansi dasar Trafo

$\mathrm{kV}^{2}$ dasar adalah tegangan sisi sekunder trafo

MVA $_{\text {dasar }}$ adalah kapasitas daya trafo

\subsection{Menghitung Impedansi Trafo}

Menghitung impedansi trafo menggunakan Persamaan (3) sebagai berikut [2] :

$$
Z_{t}=12 \% \times Z_{d}
$$

Keterangan :

$Z_{t}$ adalah Impedansi Trafo

$Z_{d}$ adalah impedansi dasar trafo

\subsection{Menghitung Reaktansi Trafo}

Menghitung reaktansi trafo menggunakan Persamaan (4) sebagai berikut [2]:

$$
X_{t}=Z_{t} x Z_{d}
$$

Keterangan

$X_{t}$ adalah Impedansi reaktansi trafo

$Z_{t}$ adalah Impedansi trafo

$Z_{d}$ adalahlmpedansi dasar trafo

\subsection{Menghitung Impedansi Sumber} Trafo

Perhitungan impedansi sumber trafo menggunakan Persamaan (5) sebagai berikut [2]:

$$
Z_{s}=\frac{\left(k V_{L L}\right)}{M V A_{h s}}
$$

Keterangan :

$Z_{S}$ adalah impedansi sumber

$k V_{L L}$ adalah tegangan dasar

$M V A_{h s}$ adalah daya hubung singkat

\subsection{Menghitung $Z_{1}$ Ekivalen dan $Z_{2}$} Ekivalen

Menghitung $Z_{1}$ ekivalen dan $Z_{2}$ ekivalen menggunakn Persamaan (6) sebagai berikut [2] :

$$
Z_{1 e k i} \text { dan } Z_{2 e k i}=Z_{d}+Z_{s}
$$

Keterangan :

$Z_{1 e k i}$ adalah impedansi ekivalen urutan positif

$Z_{2 e k i}$ adalah impedansi ekivalen urutan negatif

2.7 Menghitung Arus Hubung Singkat Satu Phasa ke Tanah Sebelum Putusnya Pengawatan NGR $40 \mathrm{Ohm}$

Perhitungan arus hubung singkat satu phasa ke tanah sebelum putusnya 
pengawatan NGR 40 Ohm menggunakan Persamaan (7) sebagai berikut [2] :

$$
I_{n g r}: I_{1 \varnothing 20}=\frac{V_{s} \cdot 1000}{\sqrt{3} \cdot N G R}
$$

Keterangan :

$I_{n g r}$ adalah nilai arus pada NGR

$I_{1} \varnothing_{20}$ adalah arus hubung singkat satu phasa sisi $20 \mathrm{kV}$

$\mathrm{V}_{\mathrm{S}}$ adalah tegangan pada sisi sekunder

2.8 Menghitung Arus Hubung Singkat Satu Phasa ke Tanah saat Putusnya Pengawatan NGR 40 Ohm

Menghitung arus hubung singkat satu phasa ke tanah saat putusnya pengawatan NGR 40 Ohm menggunakan persamaan (8) sebagai berikut [2] :

$$
\frac{V}{Z}=\frac{3 x V_{p h}}{2\left(Z_{1 e k i}+Z_{2 e k i}\right)+Z_{0 e k i}}
$$

Keterangan :

$V$ adalah tegangan sumber

$\mathrm{Z}$ adalah impedansi jaringan (Ohm)

$\mathrm{V}_{\mathrm{ph}}$ adalah tegangan fasa

\subsection{Restricted Earth Fault (REF)}

Relai gangguan tanah terbatas atau REF berfungsi untuk mengamankan trafo bila terjadi gangguan satu fasa ke tanah di dekat titik netral trafo yang tidak dirasakan oleh relai differensial dalam mengamankan dari gangguan hubung singkat satu phasa ke tanah di dalam belitan trafo.

REF dipasang pada trafo daya yang titik netralnya ditanahkan langsung (solid) atau melalui tahanan (NGR) 40 Ohm. REF diperlukan karena sensitifitas relai differensial sangat terbatas, terutama dalam mendeteksi terjadinya hubung singkat di dekat titik netral [3].

Perhitungan setting relai ini mengacu pada buku petunjuk setting (instruction manual book) yang memang diperuntukan relai REF dalam perhitungan nantinya menggunakan data dari besarnya arus hubung singkat satu phasa ke tanah pada trafo dengan titik netral yang ditanahkan melalui pentanahan titik netral. Selanjutnya hasil perhitungan akan dibandingkan dengan setting relai yang ada sehingga lebih jelas fungsi dari relai REF tersebut untuk mengamankan gangguan hubung singkat satu phasa ke tanah pada internal trafo. Dalam perhitungan setting relai REF diperlukan persamaan mengacu pada buku pedoman [4] :

a. Setting arus relai $\left(I_{R}\right)$
Perhitungan setting arus relai menggunakan persamaan (9) sebagai berikut [3]:

$$
I_{\text {mean }}=\sqrt{I_{\text {max }} x I_{\text {min }}}
$$

$I_{R}=g=10 \%+\left[\frac{I_{\text {max }}-I_{\text {mean }}}{I_{\text {mean }}} \times 100 \%\right]$

Keterangan :

Imean adalah arus primer pada tap pertengahan

$I_{\max }$ adalah arus primer pada tap tertinggi

$\mathrm{I}_{\min }$ adalah arus primer pada tap terendah

$\mathrm{g}=10 \%$ adalah basic setting

b. Sensitifitas arus primer $\left(I_{P}\right)$

Perhitungan sensitifitas primer menggunakan persamaan (11) sebagai berikut [3]:

$$
I_{p}=N x\left\{I_{R}+\left(n+I_{E}\right)\right\}
$$

Keterangan :

$\mathrm{N}$ adalah ratio trafo arus yang terpasang $\mathrm{n}$ adalah jumlah trafo arus yang di paralel $\mathrm{I}_{\mathrm{E}}$ adalah arus magnetisasi trafo arus

c. Setting tegangan relai $\left(\mathrm{V}_{\mathrm{S}}\right)$ Menghitung setting tegangan relai menggunakan persamaan (12) sebagai berikut [3]:

$$
V_{S}=\frac{I_{h s \text { max trafo }}}{N} x\left(R_{C t}+2 R_{\text {loop }}\right)
$$

Keterangan :

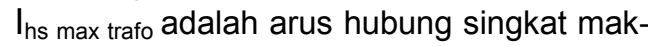
simal pada trafo daya

$\mathrm{R}_{\mathrm{Ct}}$ adalah tahanan belitan skunder trafo arus

$\mathrm{R}_{\text {loop }}$ adalah tahanan pengawatan dari trafo arus sampai ke relai

\section{d. Tegangan knee point $\left(V_{K}\right)$}

Perhitungan tegangan knee point menggunakan persamaan (13) sebagai berikut [3]

$$
V_{K}=2 \times V_{S}
$$

Keterangan :

$\mathrm{V}_{\mathrm{S}}$ adalah setting tegangan relai

e. Setting tahanan stabiliser relai (RST)

Perhitungan setting tahanan stabilisier relai menggunakan persamaan (14) sebagai berikut [3]:

$$
R_{S T}=\frac{V_{S}}{I_{R}}-\frac{V_{A}}{I_{R}^{2}}
$$

Keterangan :

$\mathrm{V}_{\mathrm{S}}$ adalah setting tegangan relai

$\mathrm{V}_{\mathrm{A}}$ adalah burden relai

$\mathrm{I}_{\mathrm{R}}$ adalah setting arus relai

2.10 Menentukan Nilai TMS (Time Multi Setting) untuk Tiap Gangguan Hubung Singkat pada Relai Trafo 
Hasil perhitungan arus gangguan hubung singkat, selanjutnya digunakan untuk menentukan nilai setelan waktu TMS. Karakteristik dari relai inverse adalah relai baru akan bekerja bila yang mengalir pada relai tersebut melebihi besarnya arus setting (Is) yang telah ditentukan dan lamanya waktu relai bekerja untuk memberikan komando trupping adalah paling lambat sesuai waktu setting (Ts) yang dipilih. Setelah mengetahui jenis relai invers yang digunakan maka nilai TMS dapat diketahui melalui persamaan berikut [5] :

a. TMS hubung singkat satu phasa ke tanah

Perhitungan TMS hubung singkat satu phasa ke tanah menggunakan persamaan (15) sebagai berikut [5]:

$$
T M S=t_{\text {set }} x \frac{\left(\left(\frac{I_{\text {f } 1 \varnothing}}{I_{\text {set } \text { primer }}}\right)^{0,02}-1\right)}{0,14}
$$

Nilai TMS yang telah ditentukan dapat digunakan untuk mencari nilai waktu tunda (td) relai pada saat terjadi gangguan berikut adalah persamaan untuk mencari nilai waktu tunda kerja (td) yaitu :

\subsection{Waktu Kerja Relai saat Gangguan Hubung Singkat Satu Phasa ke Tanah \\ Perhitungan nilai waktu kerja saat} gangguan hubung singkat satu phasa ke tanah dapat dihitung sebagai berikut [5] :

$$
t=\frac{T M S \times 0,14}{\left.\left(\frac{I_{f 1 \varnothing}}{I_{\text {set primer }}}\right)^{0,02-1}\right)}
$$

\subsection{Analisis Gangguan Satu Phasa ke Tanah pada Belitan Trafo}

Fungsi relai REF adalah untuk mengamankan gangguan satu phasa ke tanah yang terjadi pada internal trafo akibat sensitifitas dari relai differensial yang terbatas maka dalam analisis gangguan pada " $\mathrm{X} \%$ " belitan trafo perlu diketahui agar manfaat pemasangan relai REF menjadi nyata untuk meningkatkan keandalan proteksi trafo [6].

a. Jika terjadi gangguan pada $100 \%$ belitan trafo sisi skunder ke tanah maka besarnya arus gangguan satu phasa ke tanah adalah If.

b. Maka pada gangguan di titik "X\%" kumparan sisi skunder ke tanah besar arus gangguan adalah sebagai berikut [6] :

$$
\frac{X}{100} \times I_{f}
$$

\section{METODE PENELITIAN}

\subsection{Tahapan Penelitian}

Analisis dalam penelitian ini dilakukan dalam beberapa tahapan sebagai berikut.

a. Pengumpulan data transformator 3 Gardu Induk Nusa Dua.

b. Pengumpulan data relai Restricted Earth Fault.

c. Melakukan perhitungan arus hubung singkat satu phasa ketanah sebelum dan sesudah putusnya pengawatan NGR (Neutral Ground Resistor) $40 \quad$ Ohm pada transformator 3 Gardu Induk Nusa Dua

d. Melakukan perhitungan setting arus relai REF (Restricted Earth Fault) pada transformator 3 Gardu Induk Nusa Dua terhadap gangguan hubung singkat satu phasa ketanah saat putusnya pengawatan NGR 40 Ohm

4. HASIL DAN PEMBAHASAN

4.1 Sistem pengaman Trafo 3 Gardu Induk Nusa Dua

Pada analisis perhitungan ini, akan lebih membahas tentang proteksi gangguan arus lebih pada trafo khususnya pada gangguan didekat titik netral trafo, maka diperlukan sistem pengaman yang pada dasarnya berfungsi untuk melepaskan atau memutus bagian yang terkena gangguan, sehingga arus bisa padam dan gangguan tidak sampai mengenai bagian lain.

\subsection{Data Trafo Gardu Induk}

Data - data yang digunakan dalam perhitungan dapat dilihat pada Tabel 1 sebagai berikut :

Tabel 1. Data Trafo 3 Gardu Induk Nusa Dua

\begin{tabular}{|l|c|}
\hline Daya & $60 \mathrm{MVA}$ \\
\hline Impedansi Trafo & $12 \%$ \\
\hline Tegangan Primer & $150 \mathrm{kV}$ \\
\hline Tegangan Sekunder & $20 \mathrm{kV}$ \\
\hline Belitan Bintang & Ynyn0(d1) \\
\hline I Nominal $150 \mathrm{kV}$ & $230,95 \mathrm{~A}$ \\
\hline I Nominal $20 \mathrm{kV}$ & $1732,1 \mathrm{~A}$ \\
\hline Ratio C.T Primer $(150 \mathrm{kV})$ & $400: 1$ \\
\hline Ratio C.T Sekunder $(20 \mathrm{kV})$ & $2000: 5$ \\
\hline Merek & Unindo \\
\hline NGR & $40 \Omega$ \\
\hline Arus hubung singkat trafo $\left(\mathrm{I}_{\mathrm{ns}}\right)$ & $9,72156 \mathrm{kA}$ \\
\hline Arus primer pada tap terendah $\left(\mathrm{I}_{\min }\right)$ & $148 \mathrm{~A}$ \\
\hline Arus primer pada tap tertinggi $\left(I_{\max }\right)$ & $190 \mathrm{~A}$ \\
\hline \multicolumn{2}{|c}{ (Sumber : PLN 2015$)$} \\
\hline
\end{tabular}

(Sumber : PLN, 2015)

\subsection{Perhitungan Arus Hubung Singkat} Satu Phasa ke Tanah

Gangguan arus hubung singkat satu phasa ke tanah bisa terjadi di dalam trafo, berikut adalah gangguan arus hubung singkat satu phasa ke tanah sebelum putusnya 
kawat NGR dan sesudah putusnya kawat NGR :

a. I $I_{\text {hs }} 1 \varnothing$ tanah pada sisi $20 \mathrm{kV}$ sebelum putusnya kawat NGR menggunakan persamaan sebagai berikut :

$$
\begin{aligned}
I_{N G R}: I_{1 \emptyset 20} & =\frac{V_{s} \cdot 1000}{\sqrt{3} \cdot N G R} \\
& =\frac{20.1000}{\sqrt{3} \cdot 40} \\
& =\frac{20.1000}{173.40} \\
& =288,675 \mathrm{~A}
\end{aligned}
$$

b. $I_{\text {hs }} 1 \varnothing$ tanah pada sisi $20 \mathrm{kV}$ saat putusnya kawat NGR

Perhitungan nilai arus hubung singkat satu phasa ke tanah sesudah putusnya kawat NGR, maka diperlukan nilai dari perhitungan daya hubung singkat, reaktansi trafo, impedansi sumber trafo, impedansi urutan positif dan urutan negatif sebagai berikut :

1. Daya Hubung Singkat Trafo Mnghitung daya hubung singkat trafo menggunakan Persamaan (1) sebagai berikut :

$$
\begin{aligned}
M V A_{h s} & =\sqrt{3} \times k V_{L L} \times I_{h s} M V A \\
& =1,732 \times 20 \times 9,72156 \\
& =336 M V A
\end{aligned}
$$

2. Impedansi Dasar Trafo

Menghitung impedansi dasar trafo menggunakan Persamaan (2) sebagai berikut :

$$
\begin{aligned}
Z_{d} & =\frac{\mathrm{kV}_{\text {dasar }}^{2}}{\mathrm{MVA}_{\text {dasar }}} \\
Z_{d} & =\frac{20^{2}}{60} \\
& =\frac{40.000}{60}=6,670 \mathrm{hm}
\end{aligned}
$$

3. Impedansi Trafo

Perhitungan Impedansi Trafo menggunakan Persamaan (3) sebagai berikut :

$$
\begin{aligned}
Z_{t} & =12 \% \times Z_{d} \\
& =12 \% \times 6,67 \mathrm{Ohm} \\
& =0,8004 \mathrm{pu}
\end{aligned}
$$

\section{Reaktansi Trafo}

Perhitungan reaktansi trafo menggunakan Persamaan (4) sebagai berikut :

$$
X_{t}=Z_{t} x Z_{d}
$$

$$
\begin{aligned}
& =0,8004 \times 6,67 \\
& =5,34 \text { Ohm }
\end{aligned}
$$

5. Impedansi Sumber Trafo

Perhitungan impedansi sumber trafo menggunakan Persamaan (5) sebagai berikut :

$$
\begin{aligned}
Z_{s} & =\frac{\left(k V_{L L}\right)}{M V A_{h s}} \\
& =\frac{20^{2}}{336} \\
& =1,1900 \mathrm{hm}
\end{aligned}
$$

6. Impedansi Urutan Positif dan Negatif

Perhitungan impedansi urutan positif dan negatif menggunakan Persamaan (6) sebagai berikut:

$$
\begin{aligned}
Z_{1 e k i} \operatorname{dan} Z_{2 e k i} & =Z_{d}+Z_{s} \\
& =6,67+1,190 \\
& =7,86 \text { Ohm } \\
X_{0} & =3 \times X_{t} \\
& =3 \times 5,34 \\
& =7,86 \text { Ohm } \\
Z_{0 e k i} & =X_{0}+3 \times 0,7 \\
& =16,02+3 \times 0,7 \\
& =23,46 \text { Ohm }
\end{aligned}
$$

Berdasarkan nilai yang di dapat dari perhitungan diatas maka, $I_{\text {hs }} 1 \emptyset$ ke tanah pada sisi $20 \mathrm{kV}$ saat putusnya kawat NGR menggunakan Persamaan (7) sebagai berikut :

$$
\begin{aligned}
I=\frac{V}{Z} & =\frac{3 x V_{p h}}{2\left(Z_{1 e k i}+Z_{2 e k i}\right)+Z_{0 e k i}} \\
& =\frac{3 \times 20000 / \sqrt{3}}{2(7,86)+23,46} \\
& =\frac{34641,016}{39,18} \\
& =884,15 \mathrm{~A}
\end{aligned}
$$

\subsection{Perhitungan Nilai Setting Arus pada Relai REF}

Perhitungan untuk menentukan setting relai REF adalah sebagai berikut :

Data - data yang digunakan :

1. Ratio trafo arus (N) adalah $2000 / 5 \mathrm{~A}$

2. Resistansi kumparan sekunder trafo arus $\left(R_{\mathrm{CT} 2}\right)$ adalah 3,0 Ohm

3. Arus magnetisasi trafo arus adalah 0,1 
4. Jumlah trafo arus yang diparalel (n) adalah 4

5. Resistansi loop $\left(2 \mathrm{R}_{\mathrm{L}}\right) \quad$ adalah 2,5 Ohm

6. Power burden relai REF adalah 1,0 VA

7. Resistansi eksternal relai adalah $1,5 \mathrm{k}$ Ohm

Perhitungan nilai $I_{\text {mean }}$ dapat dihitung dengan Persamaan (8) sebagai berikut :

$$
\begin{aligned}
I_{\text {mean }} & =\sqrt{I_{\text {max }} x I_{\text {min }}} \\
I_{\text {mean }} & =\sqrt{190 \times 148} \\
& =167,6
\end{aligned}
$$

Setting sensitivitas pengaman trafo dapat dihitung dengan persamaan (9) sebagai berikut :

$$
\begin{gathered}
g=10 \%+\left[\frac{I_{\text {max }}-I_{\text {mean }}}{I_{\text {mean }}} \times 100 \%\right] \\
g=10 \%+\left[\frac{190-167,6}{167,6} \times 100 \%\right] \\
g=23,3 \%
\end{gathered}
$$

Dari perhitungan diatas diperoleh :

$\mathrm{I}_{\mathrm{R}}=23,3 \%$ dari 1 Ampere $=$ 0,233 Ampere

Perhitungan sensitivitas arus primer $\left(\mathrm{I}_{\mathrm{P}}\right)$ dapat dihitung dengan Persamaan (10) sebagai berikut :

$$
\begin{aligned}
& I_{P}=N x\left\{I_{R}+\left(n x I_{E}\right)\right\} \\
& I_{P}=\frac{2000}{5} \times\{0,233+(4 \times 0,1)\} \\
& I_{P}=252 \mathrm{~A}
\end{aligned}
$$

Setting tegangan minimum $\left(\mathrm{V}_{\mathrm{S}}\right)$ dapat dihitung dengan Persamaan (11) sebagai berikut :

$$
\begin{gathered}
V_{S} \geq \frac{I_{h s \max \text { trafo }}}{N} x\left(R_{C T}+2 R_{\text {loop }}\right) \\
V_{S}=\frac{9720}{400} x(3+2,5) \\
V_{S}=133,65 \mathrm{~V}
\end{gathered}
$$

Nilai tegangan knee point $\left(\mathrm{V}_{\mathrm{K}}\right)$ dapat dihitung dengan Persamaan (12) sebagai berikut :

$$
\begin{aligned}
V_{K} & =2 \times V_{S} \\
V_{K} & =2 \times 133,65 \\
& =267,3
\end{aligned}
$$

Nilai tahanan stabiliser relai REF dapat dihitung dengan menggunakan Persamaan (13) sebagai berikut :

$$
\begin{aligned}
R_{S T} & =\frac{V_{S}}{I_{R}}-\frac{V A}{I_{R}^{2}} \\
& =\frac{133,65}{0,233}-\frac{1,0}{0,233^{2}} \\
& =573,6-18,45 \\
& =555 \mathrm{Ohm}
\end{aligned}
$$

Jadi nilai tahanan stabiliser $\left(R_{S T}\right)$ relai $R E F$ sesuai perhitungan adalah $555 \mathrm{Ohm}$.

\subsection{Setting Relai yang Terpasang}

Fasilitas basic setting yang ada pada relai REF model MCAG - 14C 1BB0005B terpasang pada pengaman trafo 3 Gardu Induk Nusa Dua adalah :

$\mathrm{I}_{\mathrm{S}}: 0,1 \cdot 0,15 \cdot 0,2 \cdot 0,25 \cdot 0,3 \cdot 0,35 \cdot 0,4 \mathrm{~A}$

Frekuensi $=50 \mathrm{HZ}$

$\mathrm{I}_{\mathrm{P}}=180 \mathrm{~A}$

$\mathrm{V}_{\mathrm{S}}=133 \mathrm{~V}$

Relai di setting pada arus $\left(I_{R}\right): 0,2 \mathrm{~A}$

Dengan tahanan stabiliser $\left(\mathrm{R}_{\mathrm{ST}}\right): 610 \mathrm{Ohm}$

Sesuai perhitungan didapatkan setting relai $R E F " I_{R}$ " = 0,233 Ampere. Setting arus relai yang terpasang " $I_{R}$ " $=0,2$ Ampere. Perbedaan nilai setting REF yang terjadi antara hasil perhitungan dengan yang terpasang dilapangan, karena terbatasnya fasilitas setting pada relai tersebut. Sehingga setting yang ada mengacu pada basic setting normal trafo $(g=0,2)$ yang berpedoman pada buku setting relai $1 \mathrm{MDB}$ 04005-EN ABB, dengan demikian analisis setting relai diatas adalah benar.

\subsection{Perhitungan Nilai TMS (Time Multi Setting) pada Relai Trafo}

Nilai TMS untuk gangguan hubung singkat satu phasa ketanah dapat dihitung dengan Persamaan (14) sebagai berikut :

$$
\begin{aligned}
T M S & =t_{\text {set }} x \frac{\left(\left(\frac{I_{f 1 \emptyset}}{I_{\text {set } \text { primer }}}\right) 0,02-1\right)}{0,14} \\
& =0 \frac{\left(\left(\frac{884,15 \times 10^{3}}{0,233}\right) 0^{0,02}-1\right)}{0,14} \\
& =0
\end{aligned}
$$

\subsection{Perhitungan Waktu Kerja Relai}

Waktu kerja relai pada saat gangguan hubung singkat satu phasa ke tanah dapat 
dihitung berdasarkan dari nilai TMS yang telah dihitung sebelumnya.

a. Waktu Kerja Relai saat Gangguan Hubung Singkat Satu Phasa ke Tanah

Perhitungan waktu kerja saat gangguan hubung singkat satu phasa ke tanah dengan menggunakan Persamaan (15) sebagai berikut :

$$
\begin{aligned}
t & =\frac{T M S \times 0,14}{\left(\left(\frac{I_{f 1 \emptyset}}{I_{\text {set }} \text { primer }}\right) 0,02-1\right)} \\
& =\frac{0 \times 0,14}{\left(\left(\frac{884,15}{0,233}\right)^{0,02}-1\right)} \\
& =0 \text { detik }
\end{aligned}
$$

\subsection{Perhitungan Simulasi Gangguan pada Belitan Trafo}

Perhitungan simulasi gangguan dengan menggunakan Persamaan (16) dalam keadaan tertentu pada belitan phasa "a" terjadi gangguan hubung singkat satu phasa ke tanah dengan jarak $30 \%$ dari titik netral trafo, sehingga :

$$
\begin{gathered}
I_{\varnothing a}=\frac{X}{100} \times I_{f} \\
I_{\varnothing a}=\frac{30}{100} \times 884,15 \\
=265,245 \mathrm{~A}
\end{gathered}
$$

Perhitungan diatas berarti terjadi gangguan ke tanah pada phasa "a" sebesar 265,245 Ampere, sehingga mengakibatkan ada arus yang mengalir menuju titik netral trafo sebesar : $265,245 \mathrm{~A}$, maka $\mathrm{I}_{\mathrm{R}}$ adalah :

$$
\begin{aligned}
& I_{0}=I_{\varnothing a}=I_{p}=265,245 \mathrm{~A} \\
& I_{R}=\left[I_{\varnothing a} x N\right]-0,4 \\
& I_{R}=\left[265,245 \times \frac{5}{2000}\right]-0,4 \\
& I_{R}=0,263 \mathrm{~A}
\end{aligned}
$$

\subsection{Analisis Hasil Perhitungan}

A. Hasil perhitungan arus hubung singkat satu phasa ke tanah
Dari hasil perhitungan arus hubung singkat satu phasa ke tanah pada trafo 3 di Gardu Induk Nusa Dua, maka didapatkan besar dari arus hubung singkat satu phasa ke tanah yang menjadi acuan untuk menghitung seting arus relai REF (Restricted Earth Fault) guna memproteksi bagian didekat titik netral trafo.

Berdasarkan hasil perhitungan arus hubung singkat pada trafo 3 Gardu Induk Nusa Dua dengan kapasitas 60 MVA, berikut adalah Tabel 2 perbandingan hasil perhitungan arus hubung singkat satu phasa ke tanah sebelum putusnya pengawatan NGR dan sesudah putusnya pengawatan NGR :

Tabel 2. Perbandingan Arus Hubung Singkat Satu Phasa ke Tanah

\begin{tabular}{|c|c|c|}
\hline No & Hasil Perhitungan & Trafo 60 MVA \\
\hline 1 & $\begin{array}{c}\text { Ihs sebelum } \\
\text { putusnya kawat } \\
\text { NGR }\end{array}$ & $288,675 \mathrm{~A}$ \\
\hline 2 & $\begin{array}{c}\text { Ihs sesudah } \\
\text { putusnya kawat } \\
\text { NGR }\end{array}$ & $884,15 \mathrm{~A}$ \\
\hline
\end{tabular}

Berikut adalah Tabel 3 perbandingan hasil perhitugan nilai setting arus pada relai REF di trafo 60 MVA :

Tabel 3. Perbandingan Setting Relai REF Antara Hasil Perhitungan dengan yang Terpasang

\begin{tabular}{|c|c|c|}
\hline $\begin{array}{c}\text { Setting pada } \\
\text { relai } R E F\end{array}$ & Hasil perhitungan & Terpasang \\
\hline $\mathrm{V}_{\mathrm{S}}$ & $133,65 \mathrm{~V}$ & $133 \mathrm{~V}$ \\
\hline $\mathrm{I}_{\mathrm{R}}$ & $0,233 \mathrm{~A}$ & $0,2 \mathrm{~A}$ \\
\hline $\mathrm{R}_{\mathrm{ST}}$ & $555 \mathrm{Ohm}$ & $610 \mathrm{Ohm}$ \\
\hline
\end{tabular}

B. Analisis perbandingan dari perhitungan arus hubung singkat satu phasa ke tanah

Analisis dari hasil perhitungan gangguan hubung singkat satu phasa ke tanah sebelum putusnya kawat NGR 40 Ohm pada trafo berkapasitas 60 MVA, bahwa hasil dari perhitungan arus gangguan hubung singkat satu phasa ke tanah tersebut adalah sebesar 288,675 A dan arus gangguan hubung singkat satu phasa ke tanah sesudah putusnya kawat 
NGR 40 Ohm adalah sebesar 884,15 A, perbedaan ini disebabkan oleh putusnya kawat NGR 40 Ohm yang menyebabkan arus gangguan huung singkat satu phasa ke tanah menjadi besar.

C. Analisis perbandingan setting relai REF sisi sekunder dan hasil perhitungan dengan Setting yang Terpasang sebagai berikut :

1. Setting relai berdasarkan perhitungan

a. Setting arus pada relai $\left(I_{R}\right)$ adalah $0,233 \mathrm{~A}$.

b. Setting tahanan stabiliser $\left(R_{S T}\right)$ adalah $555 \mathrm{Ohm}$.

c. Tegangan kerja minimum $\left(\mathrm{V}_{\mathrm{S}}\right)$ adalah $133,65 \mathrm{~V}$.

2. Setting relai terpasang

a. Setting arus pada relai $\left(I_{R}\right)$ adalah
$0,2 \mathrm{~A}$.
b. Setting tahanan stabiliser ( $\left(\mathrm{R}_{\mathrm{ST}}\right)$
adalah $610 \mathrm{Ohm}$.
c. Tegangan kerja minimum $\left(\mathrm{V}_{\mathrm{S}}\right)$
adalah $133 \mathrm{~V}$.
Perbedaan setting relai REF antara hasil perhitungan dengan yang terpasang yaitu terjadi karena :

a. Fasilitas range setting yang tercantum pada relai REF adalah : $I_{S}=0,1 \cdot 0,15 \cdot 0,2 \cdot 0,25 \cdot 0,3$. $0,35 \cdot 0,4 \mathrm{~A}$

b. Nilai setting sesuai perhitungan tidak terdapat pada fasilitas setting normal (g) yaitu : $20 \% \times 1=0,2$ Ampere, tujuannya adalah agar sensitivitas relai menjadi baik.

D. Analisis perhitungan simulasi gangguan pada belitan trafo

Berdasarkan dari perhitungan simulasi gangguan pada belitan trafo, besar arus yang mengalir pada relai REF adalah sebesar 0,263 A, sedangkan relai $\mathrm{REF}$ di setting pada $0,233 \mathrm{~A}$. Saat terjadi gangguan hubung singkat satu phasa ke tanah dengan waktu kerja 0 detik atau tanpa waktu tunda

\section{KESIMPULAN}

Kesimpulan dari analisis perhitungan skripsi ini adalah sebagai berikut :

a. Pehitungan dari arus hubung singkat satu phasa ke tanah pada trafo 3 Gardu Induk Nusa Dua dengan menggunakan NGR (Neutral Ground Resistor) 40 Ohm sebesar 288,67 A, sedangkan arus hubung singkat satu phasa ke tanah setelah putusnya kawat pentanahan NGR $40 \mathrm{Ohm}$ adalah sebesar $884,15 \mathrm{~A}$.

$b$. Sistem pengaman trafo harus dilengkapi dengan relai Restricted Earth Fault (REF) untuk mengamankan gangguan hubung singkat satu phasa ke tanah, relai REF akan bekerja saat putusnya kawat pentanahan NGR $40 \mathrm{Ohm}$, karena relai REF di setting 0 detik atau tanpa waktu tunda.

c. Analisis perhitungan setting relai REF sebagai proteksi terhadap gangguan hubung singkat satu phasa ke tanah, bahwa setting arus relai REF yang didapat adalah sebesar 0,233 Ampere. Berdasarkan hasil perhitungan simulasi gangguan arus hubung singkat satu phasa ke tanah, maka besar arus yang mengalir pada relai REF adalah sebesar 0,263 Ampere, sedangkan relai REF pada perhitungan di setting pada 0,233 Ampere. Saat terjadi gangguan hubung singkat satu phasa ke tanah pada saat putusnya kawat pentanahan NGR 40 Ohm, maka relai REF sudah bekerja untuk memutus PMT.

\section{DAFTAR PUSTAKA}

[1] T. Hutauruk, Pengetanahan Netral Sistem tenaga \& Pengetanahan Peralatan. Jakarta: Erlanga, 1991.

[2] W. William and J. . Stevenson, Analisis Sistem Tenaga. Jakarta: Erlangga, 1994.

[3] E. Napitupulu, "Relay Proteksi." PT. PLN (Persero) Unit Pendidikan dan Pelatihan Semarang - Jawa Tengah, 1995.

[4] G. Alstom, $A B B$ Protection and Control 1 MDB 04005-EN and G 14,34 High Stability Circulating Current Relays. New Dehli: Weley Estern Limited, 1992.

[5] S. Komari and W. Soekarto, "Kaidah Umum Penyetelan Rele." PT. PLN Pusdiklat, 1995.

[6] J. Karmain and Felienty, "Sistem Pengaman Tenaga Listrik." Sistem Pengaman Tenaga Listrik Jawa Bali, 1995. 